\title{
Psycho-Educational Intervention Program on Psycho-Social Problems of Internet Addiction among Nursing Students
}

\author{
Shaza Salah Elsayed Ghazy ${ }^{1}$, Omayma Abu Baker Osman ${ }^{2}$ and Naglaa Fathi Mohammed ${ }^{3}$ \\ (1) Ph.D. student of Psychiatric and Mental Health Nursing, Faculty of Nursing, Benha University, \\ Egypt, (2) Professor of Psychiatric and Mental Health Nursing Ain shams University, Egypt and (3) \\ Assistant Professor of Psychiatric and Mental Health Nursing, Benha University, Egypt
}

\section{Abstract}

Background: Internet addiction is an overuse of the internet leading to impairment of individual's psychological state both mental and emotional as well as their occupational and social interactions, so it requires adequate assessment for detection and prevention. Aim of study: Was to evaluate the effect of psycho- educational intervention program on psychosocial problem of internet addiction among nursing students. Design: Quasi-experimental design (pre-test, post-test) was utilized to conduct and achieve the aim of study. Setting: This study was conducted at Faculty of Nursing of Benha University. Sample: A purposive sample of 251 students from fourth grade, who used the internet more than six hours per day. Tools of Data collection: Three tools were used: I: Structured interviewing questionnaire it was divided in three parts: Socio-demographic data, knowledge about internet use among nursing students and knowledge about the internet addiction, II: Internet addictive behavior scale, III: Depression Anxiety\& Stress Scale (DASS). Results: Nearly half of the studied student had unsatisfactory knowledge preprogram whenever most of them had satisfactory knowledge post program implementation, more than half of the studied students had moderate level of addiction pre-program implementation, while minority of them had sever level of addiction post program implementation and nearly two thirds of studied students had moderate level of psychological problems (depression, anxiety and stress) pre-program implementation, while minority of them had severe level of psychological problems (depression, anxiety and stress) post program implementation. Conclusion: The psycho-educational intervention program had a positive effect on reducing the psycho-social problems of internet addiction among nursing students. Recommendations: Continuous monitoring and evaluating student's addictive behavior for early detecting and solving problem.

Keywords: Internet Addiction, Nursing Students, Psycho-Educational Program, Psycho-Social Problems.

\section{Introduction}

The internet is one of the most powerful instruments. The bulk of internet users are thought to be young individuals. However, the internet has a bright perspective. On the contrary, misuse of the internet frequently drives young people to other kinds of addiction. Internet addiction is described as "the unable to regulate the use of the internet which in daily activities leads to emotions of strain, worry and malfunctioning."The issue of young people's irresponsible use of the Internet has become very important and has caused mental and social difficulties, leading many to addiction (Hou et al., 2019).

Different social, psychological and physical problems contribute to internet dependence. The internet-addicted individuals suffer bodily side effects such as 
sleep upset, back strain, eye strain, etc. Such people also have familial, academic and social difficulties. Anxiety, worry and sadness are one of the worst effects of internet addiction. More and more research have shown that certain young people are obsessive in use of the internet and show a very similar addiction to alcoholism, drug addiction and pathological gambling behavior (Chi, Lin \& Zhang, 2016)

University students face a significant danger of acquiring addicted to the internet since they frequently have free and unrestricted internet access and are expected to utilize this technology for learning reasons. In fact, numerous studies have shown that addiction to the internet is more common than in the general population among teenagers and young adults. Internetaddicted university students likely to suffer a wide range of academic challenges, physical and mental health issues, behavioral problems and daily routines disruption. Internet addiction has been shown to be related to cognitive/neurological deficiency and low academic performance (Tang, 2018).

People affected by internet addictive disorders must be supervised on a multi professional level as the internet addiction problem affect many aspects of someone health (psychological, social and physical aspects).the nurse ,thus represents the professional who works as a sort of conjunction among team which care of person affected by internet addiction disorder .The nurse must deeply the definite aspects related to internet addiction and internet addiction problems and understand the special meaning of specific attitudes told by the patient. The goal of nurse job is to give back to the patients their own selfcontrol, to lead the correct management of the time to the internet, understanding its real role made to inform, interact, abolish distances (Tomaszek \& MuchackaCymerman, 2019).

The psychiatric nurse provide intake co-ordination ,assessment, treatment including counseling, group therapy and follow-up care for illness and mental health problems, provides health promotion, prevention and early detection of problematic internet use core competencies and knowledge in addictions and a full range of withdrawal management services including services using best practice treatment protocols, outreach , prescribing, counseling and provide addiction counseling using motivational interviewing techniques to help clients effect change to live out their lives that fulfill their underlying hopes, belief and values (Kates et al .,2018).

\section{Aim of the study}

The aim of the study was to evaluate the effect of psycho- educational intervention program on psychosocial problem of internet addiction among nursing students

\section{Research hypothesis:}

Proposed the psycho-educational intervention program would have a positive effect on reducing the psychosocial problems of internet addiction among nursing students

\section{Subject and methods}

\section{Research design:}

Quasi-experimental design (pre-test, post-test) was utilized to conduct and achieve the aim of this study.

\section{Setting:}

This study was conducted at the Faculty of Nursing at Benha University. 


\section{Sample:}

A purposive sample of 251 nursing students from fourth grade used internet more than 6hrs per day

\section{Tools of Data Collection:}

The data was collected using the following tools:

Tool (1): Structured Interview Questionnaire. It was developed by the researcher consisted of three parts.

Part one: Socio-demographic data: It was included all the related socio-demographic data including age, sex, residence, socio economic level and marital status

Part two: Information about internet use among nursing students.

Part three: Knowledge about the internet addiction.

The total scoring system of students' knowledge was calculated and classified in two levels as following:

- For 75-100\% was considered satisfactory level of knowledge (4-5 grades).

- For less than $75 \%$ was considered unsatisfactory level of knowledge ( $4<$ grades).

Tool II: - Internet addictive behavior scale: that was modified and developed by El-koteb, (2013). It used to measure physical problems, psychosocial problems, financial problems, withdrawal symptoms\& academic achievement .It consisted of 57 items. The response to each item is given based on a 3 Likert scale never (1), sometimes (2) and always (3).

\section{Scoring system:}

- Mild internet addiction scored as (<69): Average online users Moderate
- Moderate internet addiction scored as (69< 120): Those experiencing frequent problems due to internet usage.

- Excessive internet addiction scored as (120-171) degree: Those having significant and sever problems caused internet usage

Tool III: Depression Anxiety Stress Scale: created by (Lovibond \& Lovibond, 1995). The DASS consists of 42 articles. This is a brief, self-reported version to evaluate the intensity of stress, anxiety and depression symptoms. There are fourteen items in each of the three subscales.

Scoring system for each subscale (DASS):

The student's answers were distributed by (4) scale, ranging from not applicable at all to me (0) and highly applicable to me (3).

According to the statistical analysis, every subscale was allocated to sadness, anxiety and stress:

Mild: marked as (0-13), moderate: marked as (14-20) and high marked as (21-42)

The total scoring of DASS: from (0-126) as following:

Mild psychological issues: (0-41)

Moderate difficulties in psychology: (42-83)

High psychological difficulties: (84-126).

Content validity and Reliability:

The validity of tools had done through five expertise professors of Psychiatric \& mental Health Nursing Specialties, from different Faculties of Nursing. The dependability of the tools was evaluated by means of the Cronbach Alpha Coefficient test by evaluating their internal consistency as following: 


\begin{tabular}{|l|c|c|}
\hline \multicolumn{1}{|c|}{ Tools } & $\begin{array}{c}\text { No of } \\
\text { items }\end{array}$ & $\begin{array}{c}\text { Cronbach } \\
\text { Alpha } \\
\text { Coefficient }\end{array}$ \\
\hline $\begin{array}{l}\text { Knowledge about } \\
\text { internet addiction }\end{array}$ & 5 & 0.813 \\
\hline $\begin{array}{l}\text { Internet addictive } \\
\text { scale }\end{array}$ & 57 & 0.840 \\
\hline $\begin{array}{l}\text { Depression, Anxiety, } \\
\text { Stress scale }\end{array}$ & 42 & 0.995 \\
\hline
\end{tabular}

\section{Pilot study}

A pilot study was carried out after the adaptation of the tools and before starting the data collection. It was conducted on $10 \%$ of the studied students 38 students from fourth grade

\section{Ethical Consideration:}

Before conducting the study the participants were assured about confidentiality and anonymity of their obtained information throughout the study. They were informed about their right to refuse to participate in the study and the right to withdraw from the study at any time.

\section{Field work:}

The study was carried out from the middle of October 2020 to middle of May 2021

\section{Development of psycho-educational intervention program :}

The psycho-educational intervention program was developed by the researcher after a thorough review of the related literatures and after making the pilot study. The psycho-educational intervention program aimed to evaluate the effect of psycho- educational intervention program on psychosocial problem of internet addiction among nursing students. This program has a set of general objectives, and specific objectives for each session. The number of program's sessions was 11 sessions. At the beginning of each session, the researcher gives feedback about previous session.

The $\mathbf{1}^{\text {st }}$ session: acquaintance session Introduction about aim, objectives and content of the sessions. (60min) The $2^{\text {nd }}$ session: (theoretical) knowledge about internet and internet addiction (45 $\min$ ).

The $3^{\text {rd }}$ session: (theoretical) self-esteem (45 min)

The $4^{\text {th }}$ session: methods of improving self- esteem (60 min)

The $5^{\text {th }}$ session: (theoretical) Assertiveness (30 min)

The $6^{\text {th }}$ session: (practical) assertiveness skills (60 min)

The $7^{\text {th }}$ session: Time management technique to manage psychosocial problems of internet addiction (60 min).

The $\mathbf{8}^{\text {th }}$ session: (practical) effective communication skills (60 min)

Stress management techniques (meditation and Deep muscle relaxation) (90 min)

The $\mathbf{9}^{\text {th }}$ session: (practical) Stress management techniques (90 min)

The $10^{\text {th }}$ session: (practical) Cognitive restructuring to deal with negative ideas-self monologue technique (60 min)

The $11^{\text {th }}$ session: (practical) Cognitive restructuring to deal with negative ideasideas termination technique (60 min)

The12 ${ }^{\text {th }}$ session: Summary about the program sessions and post-assessment test (60 min)

\section{Implementation Phase:-}

This phase was beginning by data collection then implementation of psychoeducational intervention program.

\section{Methods of evaluation:-}

Feedback through: oral questions, redemonstration, positive participation, role play. 


\section{Evaluation Phase (post-test).}

This phase aimed to evaluate the effect of psycho- educational intervention program on psychosocial problem of internet addiction among nursing students. Fill in post - test.

\section{Statistical analysis:}

All data were collected, coded, tabulated and subjected to statistical analysis. Statistical analysis was performed by statistical Package for Social Sciences (SPSS version 20.0). Descriptive statistics were applied in the form of mean and standard deviation for quantitative variables and frequency and percentages for qualitative variables. Qualitative categorical variables were compared using chi-square test. Statistical significance was considered at $p$-value $p \leq 0.05$, and considered highly statistically significance at $\mathrm{p}$-value $\mathrm{p} \leq$ 0.001 .

\section{Results}

Table (1): Shows that nearly three fifth of studied students $(57.4 \%)$ had 22 years old also the majority of them $(81.3 \%)$ were female. Also it was found that more than half of studied $(52.6 \%)$ students had a moderate socio economic level. (90.4) were single

Figure (1): Illustrates that nearly half of them (47\%) had unsatisfactory knowledge preprogram whenever, most of them (90.8) had satisfactory knowledge post program implementation.

Figure (2): Shows that the more than half of students $(55.8 \%)$ had moderate level of addiction pre-program implementation and nearly two fifth of them $(39.8 \%)$ had an excessive level of addiction pre-program implementation whenever, nearly half of studied students $(48.2 \%)$ had a low level of addiction post-program implementation and only the minority of them $(2.0 \%)$ had an excessive level of addiction post-program implementation

Figure (3): Illustrates that nearly two fifth of studied students $(37.0 \%)$ had severe psychosocial due to excessive internet use problems pre-program implementation compared to only less than one fifth of them (17.9\%) post program implementation.

Figure (4): Shows that more than three fifth of studied students $(62.5 \%)$ had moderate level of psychological problems (depression, anxiety and stress) pre-program implementation and nearly one third of them (32.3\%) had sever level of (depression, anxiety and stress) pre-program implementation, while more than two fifth of them $(42.6 \%)$ had a low level of (depression, anxiety and stress) postprogram implementation and only the minority of them $(2.4 \%)$ had sever level of psychological problems (depression, anxiety and stress) post program implementation.

Table (2): Shows that there were no statistically significant correlation between total internet addictive scale behavior preprogram implementation and their total DASS at (pre \& post) program implementation whenever, there were a highly statistically significant correlation between total internet addictive scale behavior post-program implementation and their total DASS at (pre) program implementation $\mathrm{p}<0.001^{* *}$ and statistically significant correlation between total internet addictive scale behavior post-program implementation and their total DASS at (post) program implementation $\mathrm{p}<0.05$ 
Psycho-Educational Intervention Program on Psycho-Social Problems of Internet Addiction among Nursing Students

Table (1): Frequency and percentage distribution of studied students according to their sociodemographic characteristics $(\mathrm{N}=\mathbf{2 5 1})$.

\begin{tabular}{|c|c|c|}
\hline Socio-demographic characteristics $((\mathrm{N}=251)$. & No & $\%$ \\
\hline \multicolumn{3}{|l|}{ 1-Age } \\
\hline 21 & 107 & 42.6 \\
\hline 22 & 144 & 57.4 \\
\hline \multicolumn{3}{|l|}{ Mean \pm SD $(21.57 \pm .496)$} \\
\hline \multicolumn{3}{|l|}{ 2- Sex } \\
\hline Male & 46 & 18.3 \\
\hline Female & 205 & 81.7 \\
\hline \multicolumn{3}{|l|}{ 3- Residence } \\
\hline Urban & 114 & 45.4 \\
\hline Rural & 137 & 54.6 \\
\hline \multicolumn{3}{|l|}{ 4- Socio-economic level } \\
\hline Low & 15 & 6 \\
\hline Moderate & 132 & 52.6 \\
\hline High & 104 & 41.4 \\
\hline \multicolumn{3}{|l|}{ 5- Marital status } \\
\hline Single & 227 & 90.4 \\
\hline Married & 24 & 9.6 \\
\hline
\end{tabular}

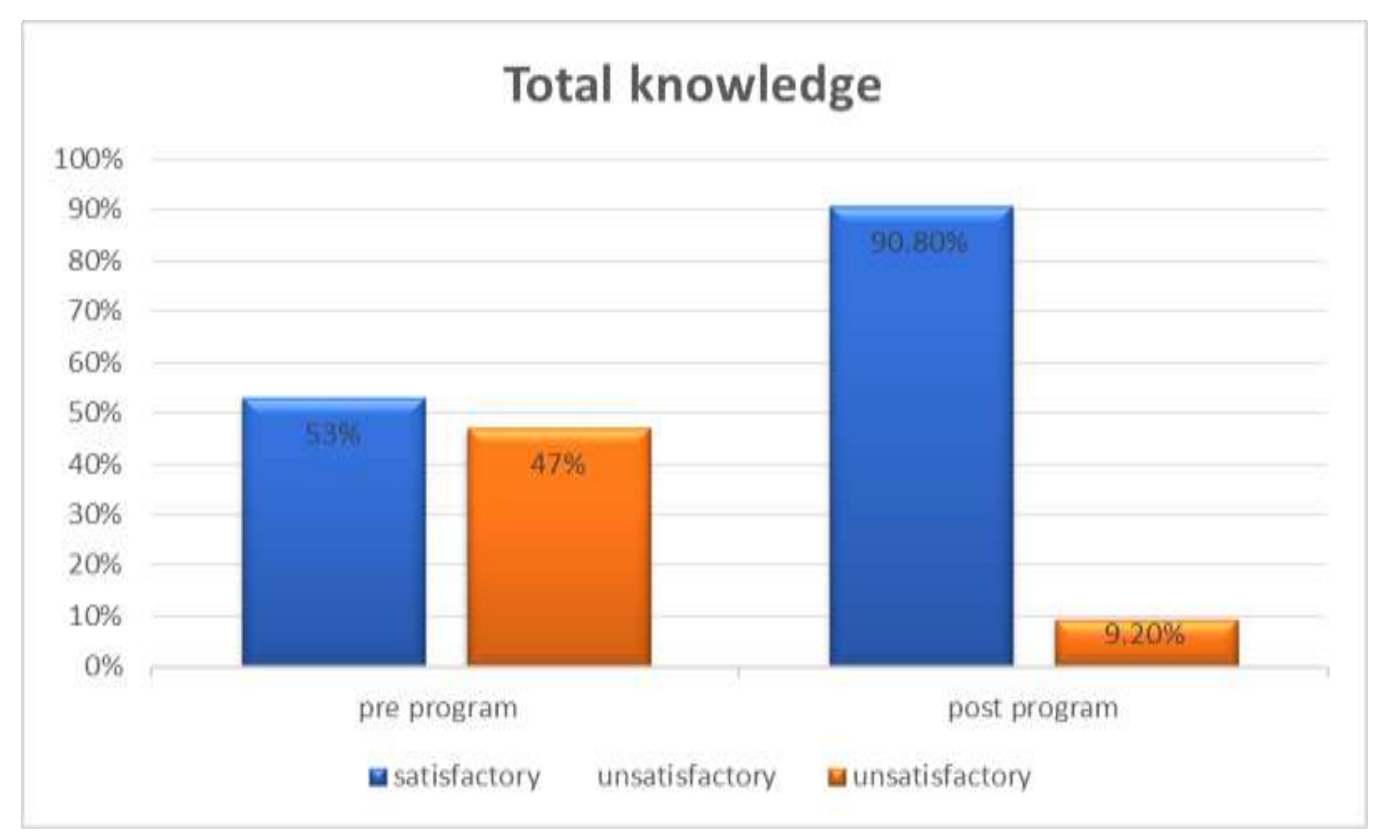

Figure (1): Distribution of studied students according to their total knowledge about internet addiction pre\& post program implementation (251). 


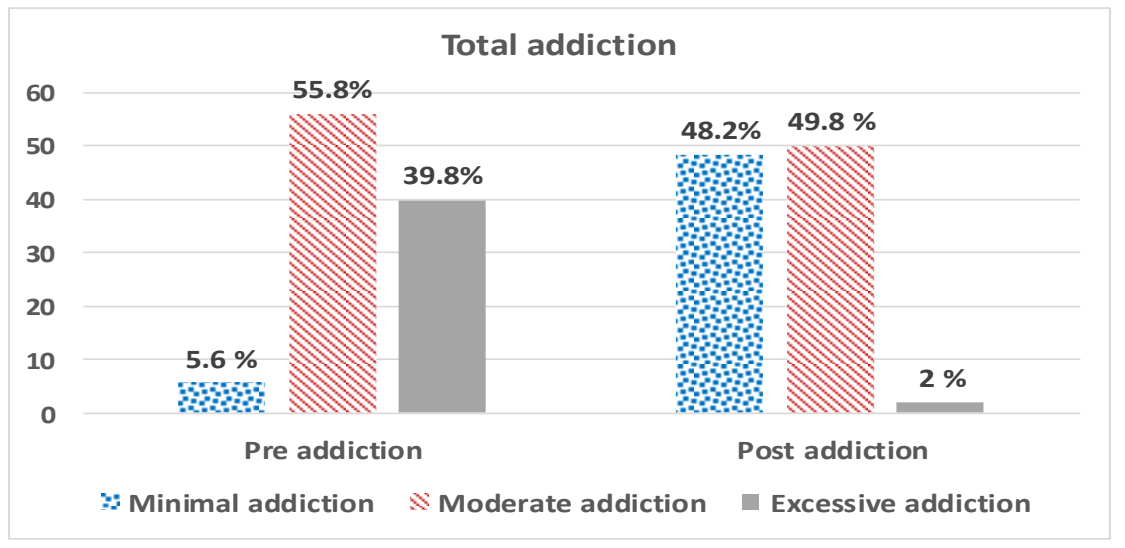

Figure 2: Distribution of studied students according to their total internet addictive scale behavior at pre \& post educational program implementation $(\mathbf{n}=251)$.

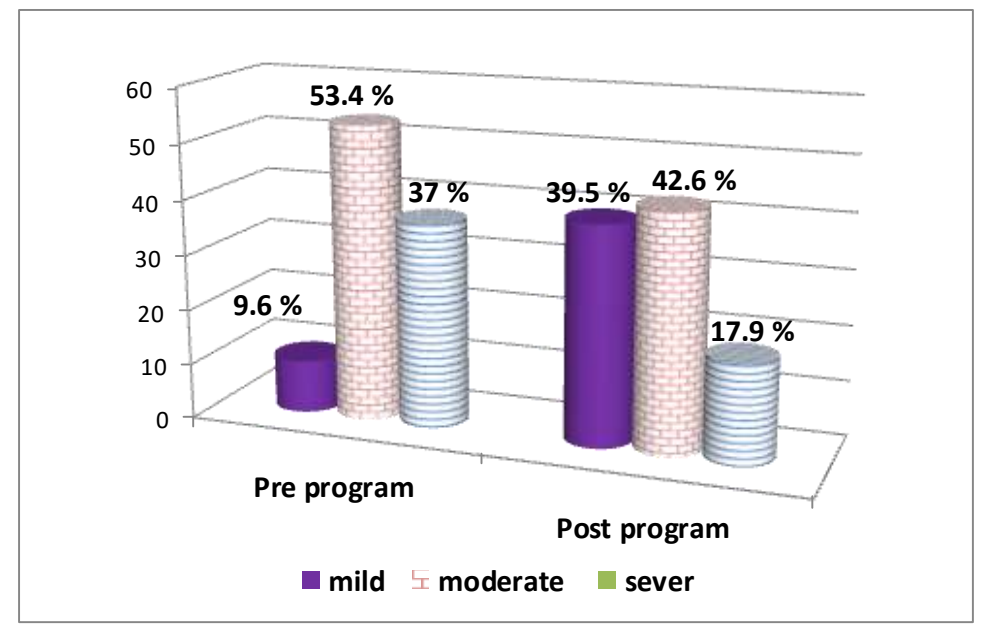

Figure (3) Distribution of studied students according to their total psychosocial problems at pre \& post educational program implementation $(n=251)$.

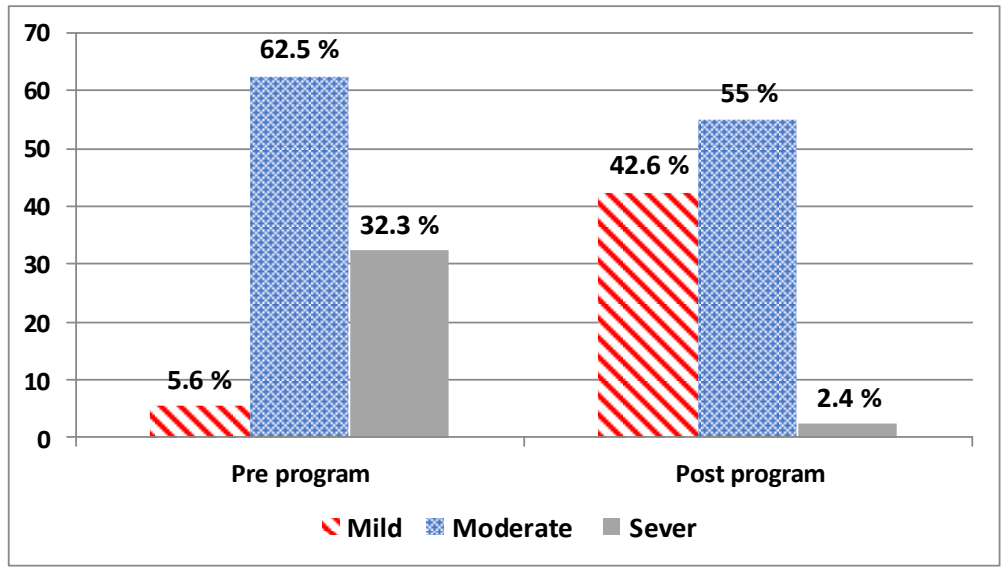

Figure (4) Distribution of studied students according to their total DASS (depression, anxiety and stress scale) at pre \& post educational program implementation $(n=251)$. 
Table (2): Correlation between total Depression, anxiety \& stress scale (DASS) \& Total internet addictive scale behavior of studied students pre and post program implementation $(\mathbf{n}=\mathbf{2 5 1})$.

\begin{tabular}{||l|c|c|c|c||}
\hline \multirow{3}{*}{$\begin{array}{c}\text { Total DASS (Depression, Anxiety\& } \\
\text { Stress Scale) }\end{array}$} & \multicolumn{2}{|c|}{ Total internet addictive scale behavior (N=251). } \\
\cline { 2 - 5 } & \multicolumn{2}{|c|}{ Pre program } & \multicolumn{2}{c|}{ Post program } \\
\cline { 2 - 5 } & $\mathrm{R}$ & $\mathrm{p}$-value & $\mathrm{R}$ & $\mathrm{p}$-value \\
\hline Total DASS pre & .020 & .748 & .352 & $000^{* *}$ \\
\hline Total DASS post & .043 & .498 & .155 & $.014^{*}$ \\
\hline
\end{tabular}

\section{Discussion}

The current result revealed that socio demographic data of the studied students with

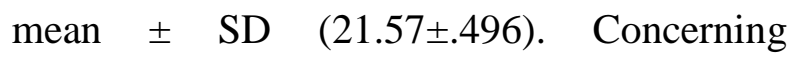
students' ages, the current study showed that nearly three fifth of studied students had 22 years old. From the researcher point of view, this result may be due to all study sample were in fourth grade at faculty of nursing in Benha university and some of them joined faculty of nursing after graduation of technical nursing institute. This result is in agreement with Çevik, \& Yildiz, (2017) who conducted a study entitled " The Roles of Perceived Social Support, Coping, and Loneliness in Predicting Internet Addiction in Nursing Students" and found that majority of students had ages ranged from 20:22 years. Conversely, this result is in disagreement with Turan, et al., (2020) who conducted a study entitled " Relationship between nursing students' levels of internet addiction, loneliness, and life satisfaction" and found that more than half of students had ages less than 20 years.

Regarding students' sex, the current study showed that the majority of them were female. From the researcher point of view, this result may be due to female tending to join faculty of nursing more than male as the faculty of nursing provided nursing students with employment chances, therefore achieving economic welfare and according toz community traditions which delegated responsibility of family member caring to females. This result is supported with Chung et al., (2019) who conducted a study entitled " Adolescent internet addiction in Hong Kong: prevalence, psychosocial correlates, and prevention" and found that majority of participants were female. On the other hand, this result is in disagreement with OsorioMolina et al., (2020) who conducted a study entitled "Smartphone addiction, risk factors and its adverse effects in nursing students" and found that majority of participants were male.

Concerning student's socioeconomic level, the current study showed that more than half of studied students had a moderate socio economic level. From the researcher point of view, this result may be due to the fact that most of Egyptian economic level is moderate and more than half of participants were from rural area, also, persons who join faculties of 
nursing may be due to their lowest socioeconomic level.

This result is accordance with Çutuk \& Çutuk, (2020) who conducted a study entitled "Investigating the Relationship between Self-Confidence, Psychological Resilience and Problematic Internet Use" and found that more than half of the participants had a moderate socio economic level. Conversely, this result is in disagreement with Çevik \& Yildiz, (2017) and found that majority of students had low socio economic level and seeking for financial support.

Regarding students' marital status, the current study illustrated that most of studied students were single. From the researcher point of view, this result may be due to majority of study sample were interested in their education and refused marriage before graduation from their faculty and being student at faculty of nursing necessitate daily attendance for lectures, clinical areas and frequent assignments which considered overload on the students . This result is in congruence with Yildiz, (2017) who conducted a study entitled "Emotion regulation strategies as predictors of internet addiction and smartphone addiction in adolescents" and found that majority of participants were single. Also, this result is in agreement with Çevik et al., (2021) who conducted a study entitled " Bullying and victimization among Turkish adolescents: the predictive role of problematic internet use, school burnout and parental monitoring" and found that majority of participants were single.

Regarding total knowledge about internet addiction pre \& post program implementation, the current study illustrated that nearly half of them had unsatisfactory knowledge preprogram whenever, most of them had satisfactory knowledge post program implementation. From the researcher point of view, this result may be due to nursing students were keen on attending the training program sessions to enhance their knowledge about internet and increase their awareness to internet addiction, also, using proper teaching strategies and different teaching skills can leads to more improvement.

This result was in agreement with Uysal \& Balci (2018) who conducted a study entitled "Evaluation of a school-based program for Internet addiction of adolescents in Turkey" and found that majority of participants had satisfactory knowledge post program implementation. Conversely, this result is in disagreement with Yildiz, (2017) and found that more than half of participants had unsatisfactory knowledge about using of internet post program implementation.

Regarding students total internet addictive scale behavior, the current study showed that the more than half of students had moderate level of addiction pre-program implementation and nearly two fifth of them had an excessive level of addiction preprogram implementation whenever, nearly half of studied students had a low level of addiction post-program implementation and only the minority of them had an excessive level of addiction post-program implementation, from the researcher point of view this may be related to the obvious effect of educational program in reducing addictive behavior.

This result is supported with Khazaei et al., (2017) who conducted a study entitled " Positive psychology interventions for internet addiction treatment" and found that nearly half of their participants had moderate level of internet and social media addiction preprogram implementation and more than half of them had excessive level of addiction preprogram which improved post program implementation, and nearly half of their 
participants had a low level of addiction postprogram implementation.

Concerning students' total psychosocial problems at pre \& post educational program implementation, the result of the present study illustrated that nearly two fifth of studied students had excessive psychosocial problems pre-program implementation compared to only less than one fifth of them post program implementation, from the researcher point of view this might be related to increased awareness of student about psychosocial problems, learned healthy behaviors through improve communication skills, self-esteem, time management ,assertiveness technique and demonstration of different activities rather than being online.

The study is agreed with Singh \& Bandyopadhyay (2020) who conducted a study entitled " Enhancing college students well-being: The psycho-spiritual well-being intervention" and revealed that there was a significant improvement in their participants psychosocial problems post program implementation whenever disagreed with Lindenberg et al., (2017) whose study revealed that there were no significant improvements of students psychosocial problems post program implementation.

Regarding students' total DASS (depression, anxiety and stress scale), the current study showed that more than three fifth of studied students had moderate level of psychological problems (depression, anxiety and stress) pre-program implementation and nearly one third of them had sever level of (depression, anxiety and stress ) pre-program implementation, while more than two fifth of them had a low level of post-program implementation and only the minority of them had sever level of psychological problems post program implementation, from the researcher point of view this might be due to the effect of educational program and effective instructions.

This result is accordance with Cristóbal et al., (2019) whose study entitled (Depressed and swiping my problems for later: the moderation effect between procrastination and depressive symptomatology on internet addiction) and found about half of studied participants had moderate level of psychological problems pre-program implementation whenever more than nearly two thirds of them had a low level of psychological problems post-program implementation and the minority of participants had sever level of psychological problems post program implementation. Conversely, this result is in disagreement with Ahmed, et al., (2021) who conducted a study entitled "Psychosocial Nursing Intervention for Enhancing Coping Skills to Reduce internet Addiction" and found that one quarter of participants had sever level of psychological problems after implementation of training program.

Regarding the correlation between total depression, anxiety \& stress scale and total internet addictive scale behavior of studied students, the current study showed that there were a highly statistically significant correlation between total internet addictive scale behavior post-program implementation and level of depression, anxiety\& stress. From the researcher point of view, this result may be due to the fact that internet addictive behavior can affect by increased knowledge that increase their understanding and reflected on their behaviors.

This result was congruent with Torres-Rodríguez et al., (2018) who conducted a study entitled "Treatment efficacy of a specialized psychotherapy program for Internet Gaming Disorder" and 
found that there were no statistically significant correlation between internet addiction pre-program implementation and their level of depression, anxiety\& stress. Conversely, this result was against with Apisitwasana et al., (2018) who found that there were no statistically significant relation between students' psychological problems and their total internet addictive behaviors after conducting the psychotherapy program.

\section{Conclusion}

The psycho-educational intervention program had a positive effect on reducing the psycho-social problems of internet addiction among nursing students. The study revealed that more than half of nursing students had moderate level of internet addiction and psychosocial problems which decreased by the implementation of psychosocial program. Level of knowledge of nursing students about internet addiction had increased after implementation of psycho-educational program.

\section{Recommendations}

1-Provide nursing students strong support facilities for counseling and recreational activities.

2-Educational program for students to enhance their social participation in family and other activities such as join to sports club, libraries, camps, charities

3-Making trusted health websites, and increase awareness through numerous channels: school campaigns, health informatics courses in educational curricula and accredited Arabic health websites.

4-Developing awareness programs specific for school and college students and other high risk groups about the physical and mental hazards maladaptive internet use are urgently needed to meet those groups 'unique needs.

\section{References}

Ahmed, N. A., Loutfi, Z., \& El Hamid Zaki, R. A. (2021). Psychosocial Nursing Intervention for Enhancing Coping Skills to Reduce internet Addiction. Ilkogretim Online, 20(5).

Apisitwasana, N., Perngparn, U., \& Cottler, L. B. (2018). Effectiveness of school-and family-based interventions to prevent gaming addiction among students in Bangkok, Thailand. Psychology research and behavior management, 11, 103.

Çevik, G. B., \& Yildiz, M. A. (2017). The Roles of Perceived Social Support, Coping, and Loneliness in Predicting Internet Addiction in Nursing Students. Journal of Education and Practice, 8(12), 64-73.

Çevik, Ö., Rıdvan, A. T. A., \& Çevik, M. (2021). Bullying and victimization among Turkish adolescents: the predictive role of problematic internet use, school burnout and parental monitoring. Education and Information Technologies, 26(3), 32033230.

Chi X, Lin L, Zhang P (2016). Internet Addiction Among College Studentsin China: Prevalence and Psychosocial Correlates. Cyberpsychol BehavSoc 19: 567-573.

Chung, T. W., Sum, S. M., \& Chan, M. W. (2019). Adolescent internet addiction in Hong Kong: prevalence, psychosocial correlates, and prevention. Journal of Adolescent Health, 64(6), S34-S43.

Cristóbal, H., Diana, R., Markus, M., Ross, D., and Beate, D. (2019). Depressed and swiping my problems for later: the moderation effect between procrastination and depressive symptomatology on internet addiction. Comput. Hum. Behav. 97, 1-9. doi: 10.1016/j.chb.2019.02.027. 
Çutuk, S., \& Çutuk, K. S. Z. A. (2020). Investigating the Relationship between SelfConfidence, Psychological Resilience and Problematic Internet Use. Studies, 7(4), 4858.

El-Kotb, H. (2013). Impact of internet addiction on psychological problems among Menofia university students.Unpublished Master thesis,Faculty of Nursing,Menofia University, Egypt.97-99.

Hou, Y., Xiong, D., Jiang, T., Song, L., \& Wang, Q. (2019). Social media addiction: Its impact, mediation, and intervention. Cyberpsychology: Journal of Psychosocial Research on Cyberspace, 13(1), article 4.

Kates, N., Arroll, B., Currie, E., Hanlon, C., Gask, L., Klasen, H., \& Williams, M. (2018). Improving collaboration between primary care anHd mental health services. The World Journal of Biological Psychiatry, 20(10): 748-765.

Khazaei, F., Khazaei, O., \& Ghanbari-H, B. (2017). Positive psychology interventions for internet addiction treatment. Comput. Hum. Behav. 72, 304-311. doi: 10.1016/j.chb.2017.02.065.

\section{Lindenberg K, Halasy K, Schoenmaekers} $\mathbf{S}$ (2017). A randomized efficacy trial of a cognitive-behavioral group intervention to prevent internet use disorder onset in adolescents: The protect study protocol, Contemp Clinical Trials Communications, 6 (25): 64-71.

Lovibond, S.H\& Lovibond, P.F. (1995). Manual for the Depression Anxiety Stress Scales ( $2^{\text {nd }}$.Ed) Sydney: Psychology Foundation.

Osorio-Molina, C., Martos-Cabrera, M. B., Membrive-Jiménez, M. J., VargasRoman, K., Martos, N. S., OrtegaCampos, E., \& Gómez-Urquiza, J. L. (2020). Smartphone addiction, risk factors and its adverse effects in nursing students: A systematic review and meta-analysis. Nurse Education Today, 104741.

Singh, K., \& Bandyopadhyay, S. (2020). Enhancing college students'well-being: The psycho-spiritual well-being intervention. Journal of Human Behavior in the Social Environment, 3(1): 1-22.

Tang So Kum, C. (2018). Depression and impulsivity mediating the relationship between social anxiety and internet addiction. International Journal of Psychology \& Behavior Analysis

Tomaszek, K., \& Muchacka-Cymerman, A. (2019). Sex differences in the relationship between student school burnout and problematic Internet use among adolescents. International journal of environmental research and public health, 16(21), 4107

Torres-Rodríguez, A., Griffiths, M. D., Carbonell, X., \& Oberst, U. (2018). Treatment efficacy of a specialized psychotherapy program for Internet Gaming Disorder. Journal of Behavioral Addictions, 7(4), 939- 952

Turan, N., Durgun, H., Kaya, H., Aştı, T., Yilmaz, Y., Gündüz, G., \& Ertaş, G. (2020).Relationship between nursing students' levels of internet addiction,loneliness andlife satisfaction. Perspectives in psychiatric care, 56(3), 598-604.

Uysal, G., \& Balci, S. (2018). Evaluation of a school-based program for Internet addiction of adolescents in Turkey. Journal of addictions nursing, 29(1), 43-49.

Yildiz, M. A. (2017). Emotion regulation strategies as predictors of internet addiction and smartphone addiction in adolescents. Journal of Educational Sciences and Psychology, 7(1). 


\section{برنامج تدخل نفسى تعليمى على المشاكل النفس إجتماعية لإدمان الإنترنت بين طلاب التمريض \\ شذا صلاح السيد غازى - أميمة ابو بكر عثمان- نجـاء فتحى حمح العطـار}

إدمان الإنترنت له آثار سلبية على الأداء الأكاديمي والعلاقات الأسرية والعقلية بالإضافة إلى الحالة

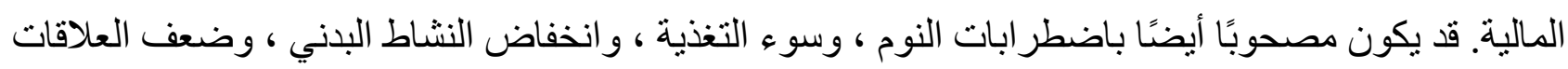

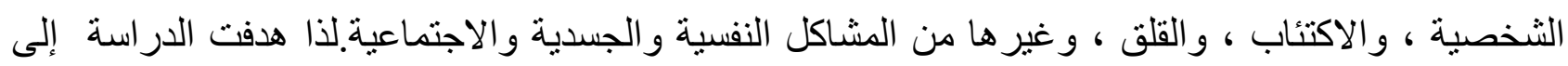

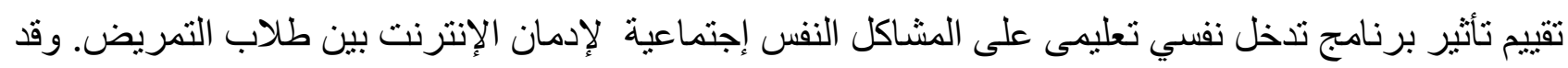
اجريت الدراسة في أجريت هذه الدراسة بكلية التمريض جامعة بنها علي طلاب الفرقة الرابعة والذين

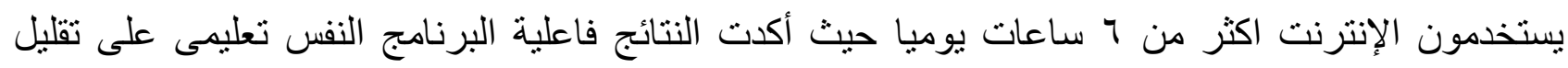

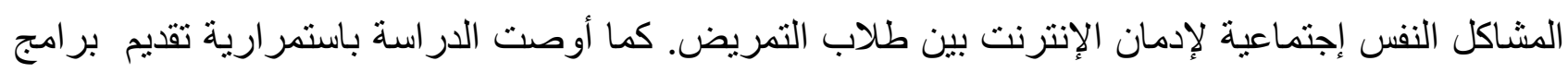

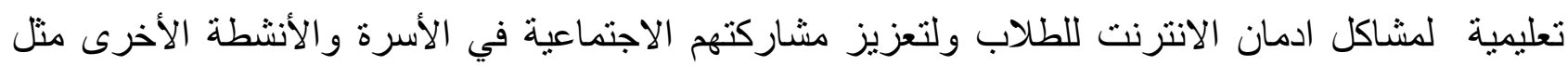
الانضمام إلى النو ادي الرياضية و الدكتبات و المعسكر ات و الجمعيات الخيرية. 